\title{
L'ASCENS SOCIAL A LA BARCELONA DEL S. XIV VIST A TRAVÉS DELS PROMOTORS DE CAPELLES DE LA SEU I DE LES GRANS ESGLÉSIES PARROQUIALS ${ }^{1}$
}

\author{
CRISTINA BORAU I MORELL ${ }^{2}$
}

Data de recepció: maig 2002

Data d'acceptació i versió final: juliol 2002

Resum: El tema d'aquest article és el mecenatge o promoció de capelles a les esglésies gòtiques com a instrument de consolidació del prestigi social. Al llarg del segle XIV es van renovar la catedral i les tres grans esglésies parroquials de Barcelona: Sta. Maria del Mar, Sta. Maria del Pi i Sant Just. Les autoritats eclesiàstiques van preveure, des del principi, que la transformació d'aquells temples romànics en els gòticsde l'actualitat seria lenta i molt cara. Per això van decidir concedir les noves capelles que s'anaven construint a persones adinerades, a canvi que paguessin un generós donatiu. Els promotors d'aquelles capelles eren, majoritàriament, mercaders i oficials reials, els sectors socials que més van prosperar en aquell context. Bona part d'aquells promotors pertanyia a famílies que ja havien iniciat l'escalada estamental anteriorment, però nosaltres ens hem centrat en els que van protagonitzar nous ascensos socials. El seguiment de la seva trajectòria s'ha realitzat a través de la documentació notarial.

Paraules clau: Segle XIV, Barcelona, Mecenatge, Catedral, Parròquia, Capelles, Mercaders, Oficials reials.

Abstract: The issue of this article is the patronage or promotion of de chapels in gothic churches as a mean of consolidation of people's social prestige. All along the XIV century the cathedral and the three parishes of Sta. Maria del Mar, Sta. Maria del Pi and Sant Just in Barcelona had been rebuilt. Church authorities had expected that changuig the romanic

'Abreviatures emprades en aquest article: $\mathrm{ACB}=$ Arxiu Capitular de Barcelona. $-\mathrm{ADB}=$ Arxiu Diocesà de Barcelona.- AHMB = Arxiu Històric Municipal de Barcelona.- AHPB = Arxiu Històric de Protocols de Barcelona.- AHPSJ = Arxiu Històric Parroquial de Sant Just.- RD = Registra Dotaliarum (ADB).

${ }^{2}$ Doctora en Història de l'Art, per la Universitat de Barcelona.

«Anuario de Estudios Medievales», 32/2 (2002), pp. 693-722 .- ISSN 0066-5061. 
churches into the the gothic style known today would be slow and expensive, that is why they decided to confer the new chapels to wealthy people who in turn were supposed to give the eclesiastical institution a generous donation. The promotors of these chapels were mostly merchants and royal civil servants who were at that time in the best social position. Most of them belonged to families who had achieved this position in the past, but we have concentrated in those who were the last ones to obtain better standards of social consideration. The monitoring of their social development has been done thoug legal documentation.

Key-words: 14th century, Barcelona, Patronage, Cathedral, Parishes, Chapels, Merchants, Royal civil servants.

\section{SUMARI}

I. Mercaders i funcionaris reials: promotors de capelles i protagonistes d'ascensos socials. II. Els mercaders promotors de capelles: tres exemples d'ascens social. III. Els oficials reials promotors de capelles: tres exemples d'ascens social. IV. Estratègies de consolidació i ascens social: orientació professional i cohesió familiar. V. Apèndix documental. VI. Illustracions.

\section{MERCADERS I OFICIALS REIALS: PROMOTORS DE CAPELLES I PROTAGONISTES D'ASCENSOS SOCIALS}

Es podria definir la Barcelona del s. XIV com una ciutat en moviment, tant pel que fa a l'estratificació social dels seus habitants com al seu traçat urbà. Mentre s'urbanitzaven nous carrers, s'eixamplaven places, s'alçaven muralles i s'ampliaven esglésies els barcelonins s'afanyaven a produir, comerciar, invertir, de manera que resulta difícil no fer referència al tòpic recurrent del dinamisme productiu, comercial i constructiu i al de la mobilitat social. Els tòpics en què ens centrarem al llarg d'aquest article són el dinamisme constructiu i la mobilitat social que, com veurem, estan més relacionats del que pot semblar. Aquell dinamisme constructiu es va manifestar de forma molt evident en l'ampliació de la Seu i de les tres grans esglésies parroquials de Barcelona: Santa Maria del Mar, Santa Maria del Pi i Sant Just, tot i que en el cas de Santa Maria del Mar sembla més correcte parlar de construcció de nova planta. Aquelles ampliacions van culminar en la total transformació de les esglésies romàniques en els temples gòtics que es conserven en l'actualitat. Les autoritats eclesiàstiques, des del principi, van preveure que aquestes obres serien molt llargues i costoses, de manera que 
van intentar garantir la continuïtat del finançament a través de diverses mesures: aplicació de les rendes dels beneficis eclesiàstics vacants a l'obra de la Seu, recaptació mitjançant fogatge entre els habitants de les demarcacions parroquials per a l'obra de les seves respectives esglésies, etc., etc. Però la configuració d'aquells nous temples, caracteritzats per l'existència de capelles perimetrals entre els contraforts de les voltes, va proporcionar un recurs de finançament addicional: l'adjudicació de les capelles que s'anaven construint a particulars adinerats a canvi de quantiosos donatius. Com veurem més endavant, sembla que l'import d'aquells donatius estava estipulat, de manera que més aviat es poden considerar com a pagaments per les capelles. Entre els particulars que van sol-licitar una capella a les autoritats eclesiàstiques per promoure destaquen clarament, per majoritaris, dos sectors socials: els mercaders i els oficials reials.

Parlar d'ascens social en la Barcelona del segle XIV és, fonamentalment, parlar de mercaders i oficials reials, sectors molt afavorits per les circumstàncies que van concórrer en el seu context. En ells van confluir el poder econòmic, el polític (ja fos al servei de la Corona o del Consell de la ciutat) $i$, en conseqüència, el prestigi social o la necessitat de consolidar-lo. Una de les manifestacions més ostensibles d'aquest potencial econòmic $i$, per tant, un dels distintius socials per excel·lència, era l'obtenció d'una d'aquelles capelles que s'anaven construint a les noves esglésies gòtiques de la ciutat, sobretot a la Seu i a les tres grans esglésies parroquials esmentades. Aquelles capelles només eren adjudicades per les autoritats eclesiàstiques als sol-licitants prou solvents per poder-ne finançar la construcció, dotar-hi un benefici eclesiàstic i proveir-les de tots els ornaments litúrgics necessaris per a la celebració del culte (calze, patena, missal, indumentària litúrgica ...) i, sovint, també de retaule. Com veurem a continuació, la suma de totes aquestes despeses suposava una inversió de capital realment considerable.

Segons la documentació consultada ${ }^{3}, \mathrm{l}^{\prime}$ import d'una capella oscil-lava entre les 100 lliures pagades per les del claustre de la catedral i les 50 que costaven les de Sta. Maria del Mar i Sant Just. L'adjudicació de la capella al sol-licitant només es feia efectiva si aquest es comprometia, davant de notari,

${ }^{3} \mathrm{ADB}$, Liber Dotaliarum; ACB, Llibre de l'Obra; AHPSJ, Llibre d'Institucions de Beneficis i Capellanies; AHPB, testaments, procures i rebuts, bàsicament.

«Anuario de Estudios Medievales», 32/2 (2002), pp. 693-722 .- ISSN 0066-5061. 
a dotar un benefici en l'altar que hi erigís, en el cas que ajornés la seva fundació per més endavant, i si estipulava els diners o els béns immobles que destinaria a la seva dotació. Pensem que aquest dot havia de produir una renda que no només garantís la manutenció del prevere designat com a beneficiat pel fundador, sinó també la dels seus successors, ja que el benefici eclesiàstic s'instituïa a perpetuïtat. Aquestes rendes beneficials oscil-laven entre les 13 i les 35 lliures, amb predomini de les situades al voltant de les 15 lliures. ${ }^{4}$ Per tant, si es volia ajornar el màxim possible el perill de devaluació de la renda beneficial, calia realitzar una dotació prou generosa.

No resulta gaire fàcil esbrinar el cost total de la dotació d'un benefici, ja que les actes de dotació tan aviat recullen ordres testamentàries d'adquirir censos que proporcionin una renda beneficial anual d'un import determinat, sense estipular la quantitat a invertir, com recullen enumeracions dels morabatins censuals percebuts sobre diverses terres i immobles que es destinaran a la renda beneficial, la suma dels quals permet deduir l'import d'aquella. Excepcionalment, en algunes ocasions el testador estipula el llegat que s'invertirà en l'adquisició de la capella, la seva ornamentació i la dotació del benefici. En aquests casos tampoc resulta fàcil deduir els imports destinats a cada cosa, ja que només coneixem amb seguretat el preu de les capelles. Per exemple, Francesc Estrada (promotor de la capella de Tots Sants, Sta. M. del Mar) va llegar 30.000 sous l'any $1355,12.000$ dels quals s' havien d'invertir in opera dicte capelle et ornamento prebiteri et calice et missalt ${ }^{5}$. D'aquests 12.000 sous (= 600 ll.) podem restar les 50 1l. que costaria la capella, de manera que encara quedarien $550 \mathrm{ll}$. només per a ornaments i parament litúrgic. El llegat de Galcerà Llull ${ }^{6}$ (que va intentar promoure la capella de sta. Marta de Sta. M. del Mar, però se li van avançar els Gualbes) l'any 1348 encara era més considerable: 20.000 sous (= 1000 lliures) per gastar en la capella i el dot beneficial, que havia de produir una renda de 15 lliures. La resta dels llegats que especifiquen l'import total invertit es redueixen als de

\footnotetext{
${ }^{4}$ Cristina BORAU, Els promotors de capelles $i$ retaules en la Barcelona del segle XIV, Barcelona, 2002 (en premsa), taules 4-7: sistemes de finançament del benefici.

${ }^{5} \mathrm{ADB}, \mathrm{RD}, \mathrm{IV}$, fols. 240r-250r.

${ }^{6} \mathrm{ADB}, \mathrm{RD}, \mathrm{VI}$, fols. $123 \mathrm{v}-128 \mathrm{v}$.

«Anuario de Estudios Medievales», 32/2 (2002), pp. 693-722 .- ISSN 0066-5061.
} 
Pere Terré ${ }^{7}$ en 1353 (capella de st. Pere, Sta. Maria del Pi), de 15.000 sous (= 750 lliures) per obtenir una renda de 34 morabatins censuals; Bernat Guillem Sabastida $^{8}$ en 1348 (capella dels sts. Joan E. i Bernat, Sant Just), amb 10.000 sous ( $=500$ lliures), 1000 dels quals (= 50 lliures) a invertir en la capella i l'altar, i Jaume Novell ${ }^{9}$ en 1323 (capella de st. Cristòfol, Seu), amb 1000 sous (= 50 lliures) destinats a la capella i l'altar, als quals s'hauria d'afegir el cost, ignorat, dels 30 morabatins censuals de renda beneficial.

Trobem també un altre document que no evidencia quin era l'import indispensable per a la dotació d'un benefici a la Seu, sinó quin resultava insuficient, tot i ser força considerable, dada que ens permet tenir una idea del preu mínim d'un dot beneficial. Es tracta de 1 'acta de dotació ${ }^{10}$ del benefici dels sts. Tomàs i Antoni de $\mathrm{P}$. de la Seu pel mercader Jaume de Rocafort (1353) en execució de l'ordre testamentària del seu pare, Salvador, tot i que aquell havia ordenat la dedicació del benefici a una altra advocació. Jaume, a més, va solicitar del Capítol la concessió d'una capella del claustre per a fundar-hi el benefici, de manera que el cost de la seva adquisició es va sumar a les 600 lliures llegades pro emendo triginta morabatinos in alodio ad opus et pro sustentatione vite prebiteri seu beneficiati ipsius presbiteratus et etiam ornamenta altaris seu capelle ipsius presbiteratus. Però, com veurem a continuació, aquella quantitat va resultar insuficient:

\footnotetext{
Et dicte sexcente libre no sufficiant ad emendum quindecim libras monete barchinonense de terno in alodio, quas quilibet instituens prebiteratum in dicta Sede, iuxta ordinacionem honorabilis Capituli dicte Sedis, emere tenetur pro sustentatione vite presbiteri seu beneficiatus ipsius presbiteratus et etiam ad emendum tres libras dicte monete quas, iuxta dictam ordinacionem, quilibet instituens prebiteratum in dicta Sede emere tenetur in alodio pro anniversaris fiendis quolibet anno in dicta Sede.
}

No tenim notícies de l'import pagat per cada peça del parament i de la indumentària litúrgica, ni tampoc pels llibres litúrgics, però tant les peces

${ }^{7} \mathrm{ADB}, \mathrm{RD}$, VII, fols. $158 \mathrm{r}-159 \mathrm{v}$.

${ }^{8}$ AHPSJ, Llibre d'Institucions de Beneficis i Capellanies, fol. 9v.

${ }^{9} \mathrm{ADB}, \mathrm{RD}, \mathrm{I}$, fol. $224 \mathrm{v}$.

${ }^{10} \mathrm{ADB}, \mathrm{RD}, \mathrm{I}$, fols. 330v-333v.

«Anuario de Estudios Medievales», 32/2 (2002), pp. 693-722 .- ISSN 0066-5061. 
d'orfebreria com els missals eren objectes cars. En canvi sí que tenim informació sobre el que pagaven pels retaules que, col-locats darrera els altars, ornaven la major part d'aquelles capelles. Els imports variaven en funció de la mida, materials (tipus de fusta, d'or, de pigments) o altres característiques de l'obra i, lògicament, de la cotització del seu artífex, però també deurien anar experimentant variacions a mesura que avançava el segle. Així, aproximadament, el seu preu oscil-laria entre les 110 lliures pagades a Pere Serra i Joan Mates, successivament, l'any 1409 pel retaule dels sts. Tomàs i Antoni de $\mathrm{P}$. de la Seu i les 45 promeses el 1370 a Pere de Valldebriga pel de sta. Maria Magdalena, també de la Seu ${ }^{11}$. Així, doncs, en virtut de totes aquestes dades, podem deduir que per obtenir una capella, dotar-hi un benefici i proveir-la de retaule s'havien d'invertir, com a mínim, unes 700 lliures.

Però, quins eren els incentius que justificaven l'enfrontament de totes aquelles despeses, i, encara més, quan sovint s'havia de competir amb d'altres aspirants per aconseguir la capella, tots prou solvents? Com a mostra d'aquella competència, tornem a l'exemple de Galcerà Llull, que en el seu testament havia disposat la promoció d'una capella a Sta. M. del Mar (sta. Marta) que, finalment, va acabar essent adjudicada a Jaume de Gualbes, perquè se li va avançar i la va començar a promoure en vida. Galcerà Llull es va quedar sense capella però el benefici que havia disposat, dedicat a sta. Marta, es va fundar a la capella promoguda per Pere de Guardiola, dedicada a sta. Anna. Menys pacíficament es va resoldre el conflicte d'interessos entre l'argenter Jaume Gracià i Francesc Estrada, que se li va avançar com Gualbes a Llull, ja que va culminar en un procés judicial ${ }^{12}$. Igualment, l'afany i la insistència dels que aspiraven a obtenir una capella arribava fins el punt que, en algun cas, havien arribat a conseguir que d'altres promotors els venguessin la seva quan ja estava a mig construir. Aquest és el cas del tresorer reial Pere Desvall, que va obtenir la cessió de la capella que estaven promovent els

\footnotetext{
${ }^{11}$ Documents publicats per Josep Maria MADURELL I MARIMON, El pintor Lluís Borrassá: su vida, su tiempo, sus seguidores y sus obras, "Anales y Boletín de los Museos de Arte de Barcelona", 7 (Barcelona 1949), 8 (1950) i 10 (1952).

${ }^{12} \mathrm{ACB}$, Speculum, II, fol. 100r.

«Anuario de Estudios Medievales», 32/2 (2002), pp. 693-722 .- ISSN 0066-5061.
} 
marmessors testamentaris de Francesc d'Eiximenis al claustre de la $\mathrm{Seu}^{13}$. Encara es trobava incepta et usque ad medium vel quasi continuata i estava situada contigua inmedia[te] portali ipsius claustri quod aperit versus meridie, és a dir, al costat de la de Pere de Marges, de la qual estava separada només pel portal del c. de la Pietat. Marges no només era un company de feina (escrivà de ració de la Tresoreria reial i senyor del castell de Mataró ${ }^{14}$ ), sinó també un amic, ja que el va designar un dels tutors de la seva filla Maria ${ }^{15}$. Davant d'aquesta competència no és estrany que Jaume de Rocafort (capella dels sts. Tomàs i Antoni de $\mathrm{P}$., Seu), al qual ja ens hem referit, confessi en l'acta de dotació haver hagut de recórrer a les seves influències per aconseguir-la: ${ }^{16}$

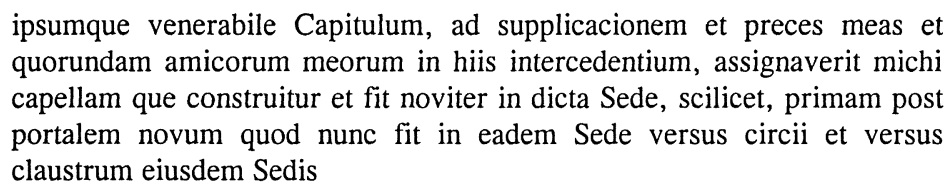

Els incentius que justificaven l'enfrontament de tots aquells tràmits i despeses per part dels qui aspiraven a promoure una capella eren, bàsicament, dos. En primer lloc, a nivell espiritual, el perdó dels pecats i la garantia de salvació eterna, gràcies a les pregàries del prevere designat com a beneficiat, adscrit a l'altar de la capella. En segon lloc, a nivell social, la gratificació consistiria en el fet que tothom sabés qui havia promogut aquella capella, qui hi estava enterrat i qui havia donat el seu retaule. Això era possible gràcies al fet que l'obtentor de la capella adquiria automàticament el dret a representar l'escut familiar en els seus murs, al carner i al guardapols del retaule, si és que decidia donar-ne un. Així se li feia entendre als marmessors testamentaris de Francesc d'Eiximenis l'any 1355 a l'acta de concessió d'una de les capelles

\footnotetext{
${ }^{13}$ AHPB, 23/3, s. f., 3-1-1375.Veg. Apèndix documental.

${ }^{14} \mathrm{AHPB}, 17 / 7$, fol. 98r, 30-5-1371.

${ }^{15}$ Ibid., fol. 98v: referència a un document del 13-10-1374.

${ }^{16} \mathrm{ADB}, \mathrm{RD}, \mathrm{I}$, fol. 331r, 2-1-1353. 
del claustre de la $\mathrm{Seu}^{17}$, posteriorment cedida, com s'ha dit, a Pere Desvall: in dicta capella possitis (...) facere signum et signa, tot et quanta ac alia quot et quanta volueritis (...) et etiam carnerium.

Així, doncs, parlar de mercaders i oficials reials en la Barcelona del s. XIV no només comporta una referència obligada al fenomen de l'ascens social, sinó també al del finançament de capelles, beneficis i retaules en les esglésies gòtiques que s'estaven alçant arreu de la ciutat, finançament en què es manifestava la puixança i el prestigi d'aquells sectors socials. Però, si bé la capella constitueix el testimoni material de l'ascens i la consolidació social d'aquells individus, en canvi són les fonts documentals les que testimonien les passes i les estrategies seguides per a la consecució de l'estatus econòmic i social. En aquest sentit trobem molts d'aquests mercaders i oficials reials que van promoure capelles relacionats amb l'exercici del poder polític, ja fos al servei de la corona ja fos al servei del Consell de la ciutat.

Bona part dels promotors de les capelles d'aquelles esglésies pertanyia a famílies que ja havien iniciat l'escalada estamental abans d'arribar ells, però nosaltres ens hem centrat en els que van protagonitzar nous ascensos socials o, si més no, van preparar el terreny perquè els protagonitzessin els seus fills. $S$ 'han seleccionat com a exemples tres mercaders i tres oficials reials, el seguiment dels quals s' ha realitzat a través del rastre deixat en la documentació de l'AHPB en el decurs de la seva trajectòria i ascens social.

\section{ELS MERCADERS PROMOTORS DE CAPELLES: TRES EXEMPLES D'ASCENS SOCIAL}

El sector dels mercaders era potser el de composició més variable en aquella societat, ja que els membres del seu estrat superior, constituit per aquells comerciants tan enriquits que es dedicaven al rendisme, podien ascendir al dels ciutadans honrats, posseïdors d'honors i propietats, mentre que el seu estrat més modest s'incrementava amb l'accés de menestrals que havien prosperat. Un dels col-lectius amb més possibilitats d'enriquiment i, per tant, d'ascendir socialment era el dels especiers o apotecaris, ja que el seu

${ }^{17}$ ACB, NP, F. de Puig, 240, s. f., 3-3-1355.

«Anuario de Estudios Medievales», 32/2 (2002), pp. 693-722 .- ISSN 0066-5061. 
ofici els relacionava amb la venda del producte més lucratiu: l'espècie. La seva relació amb aquest producte derivava, en alguns casos, vers la participació en la seva importació, activitat que va afavorir l'acumulació de fortunes considerables $i$, en conseqüència, ascensos socials. Com veurem més endavant, un bon exemple d'ascens social en aquesta direcció ens l'ofereix el promotor d'una de les capelles de la Seu, Pere Safont. Els integrants d'aquell sector mercantil poden classificar-se en quatre grups: armadors de naus, canviadors, drapers i, com els anomena Batlle, "mercaders mercadejants", dedicats pròpiament a l'exercici del comerç. Totes aquestes modalitats de mercader tenien possibilitats d'acabar vivint de renda i ascendir a l'estament dels ciutadans honrats, però els que, per raó del seu ofici, sembla que ho tenien més fàcil eren els canviadors. Recordem que la Corona els sol-licitava préstecs en casos de necessitat que sovint no els podia restituir, de manera que recompensava els seus serveis concedint-los càrrrecs a l'administració reial. Un bon exemple d'ascens social en aquesta direcció ens l'ofereix el canviador Jaume de Gualbes, fill del draper del mateix nom, professió que permetia acumulacions de capital tan quantioses que alguns drapers o els seus descendents començaven a negociar com a prestamistes i acabaven esdevenint canviadors. Com Pere Safont, els Gualbes també van invertir part de la seva riquesa en la promoció d'una capella, en aquest cas a Santa Maria del Mar.

\section{1. D'apotecari a mercader: Pere Safont}

Pere Safont sembla constituir un exponent dels apotecaris que van prosperar gràcies a la seva intromissió en el comerç, molt lucratiu, d'un ingredient bàsic en el seu ofici: l'espècie. Aquesta ocupació no li venia de tradició familiar, ja que el seu pare consta com a abaixador:

Nos Petrus de Fonte, apothecarius, civis Barchinone, et Eulalie, soror eius uxorque P. de Vilario, mercatoris (...) filli et heredis ab intestato R. de Fonte, quondam baxatoris, civis predicte civitatis ... ${ }^{18}$

${ }^{18} \mathrm{AHPB}, 16 / 3$, fol. 9r, 3-2-1362.

«Anuario de Estudios Medievales», 32/2 (2002), pp. 693-722 .- ISSN 0066-5061. 
Safont apareix documentat com a apotecari des de l'any $1354^{19} \mathrm{i}$, com tants altres del seu gremi, tenia l'obrador i la seva residència al carrer del Paradís $^{20}$. A partir del 1362 consta ja com a mercader ${ }^{21}$ i des del 1369 com a domiciliat en el carrer d'en Guillem Nas (ara Gignàs) ${ }^{22}$, al quarter de Framenors. En el padró de milícia del 1389 és la seva vídua qui paga la contribució (tres arnesos) ${ }^{23}$, de manera que Safont va iniciar la promoció de la seva capella pocs anys abans de morir, l'any 1382 . En aquesta data apareix enregistrada, en els llibres de 1'Obra de la $\mathrm{Seu}^{24}$, la primera despesa relativa a la construcció d'aquella. Va dedicar-la a la santa patrona de la que, segons sembla, fou la seva única filla, Eufrasina. Allà hi va disposar no només la seva sepultura, sinó també la de la seva dona i la seva filla. La capella, que és la cinquena de l'ala del claustre que corre paral-lela al carrer de la Pietat, encara està oberta al culte, tot i que ara està dedicada a St. Ramon Nonat. Resulta ben visible el carner en el mur, així com els escuts murals amb la font brollant dels Safont.

II.2. De draper a canviador $i$ creditor del rei: Jaume de Gualbes, pare $i$ fill

El draper Jaume de Gualbes era proveïdor de la casa reial, com consta en un rebut signat al procurador de Felip de Boïl ${ }^{25}$, tresorer del rei Alfons, l'any 1338. Residia al costat de Sta. Maria del Mar, entre l'església

${ }^{19}$ AHPB, 19/19, fol. 165v, 11-11-1354.

${ }^{20} \mathrm{AHPB}, 16 / 2$, fol. 29r, maig 1359, i 23/12, fol. 77r, 20-9-1362.

${ }^{21} \mathrm{AHPB}, 16 / 3$, fol. 34r, 10-6-1362.

${ }^{22}$ AHPB, 23/20, fol. 2v, 23-4-1369.

${ }^{23}$ AHMB, CC, Fogatges: padró de milícia del 1389, Framenors, fols. 75r i $211 \mathrm{r}$.

${ }^{24} \mathrm{ACB}, \mathrm{LO}, 1379-1381$, fol. $117 \mathrm{v}, 23-8-1382$ : pagament per pedra destinada a la capella.

${ }^{25} \mathrm{AHPB}, 14 / 1$, fol. $86 \mathrm{v}, 1-7-1338$.

«Anuario de Estudios Medievales», 32/2 (2002), pp. 693-722 .- ISSN 0066-5061. 
i l'antiga peixateria ${ }^{26}$, i consta que l'any 1344 va ser conseller de la ciutat ${ }^{27}$. Segons els Registra Dotaliarum ${ }^{28}$, va promoure la capella dels sts. Mateu i Marta (Sta. Maria del Mar) juntament amb els seus germans Ferrer, Francesc i Bernat, tot i que la fundació del benefici en el seu altar es va postergar fins que no es va executar l'ordre testamentària (1348) del propi Jaume. Segons 1'Speculum de Campillo, que remarca l'existència de diversos testaments de membres d'aquella família en relació amb el benefici, els responsables de la fundació van ser els fills de Jaume, Joan i Ponç, la seva vídua, Serena, el seu nebot Francesc, fill de Francesc, els seus nebots Bernat i Simoneta, fills de Ferrer, i la vídua d'aquell, Isabel ${ }^{29}$. Tot i no aparèixer esmentat a l'acta de dotació del benefici, Jaume de Gualbes tenia un altre fill a més de Joan i de Ponç, anomenat també Jaume, que primer consta com a draper i després com a ciutadà. Jaume fill apareix en la documentació notarial com a germà de Joan i de Ponç, que consten com a hereus del seu pare ${ }^{30}$. Igualment, l'any 1354 apareix com a mercader associat amb el seu germà Ponç ${ }^{31}$. A partir de l'any 1363 Ponç consta com a soci del seu germà $\mathrm{Joan}^{32}$, mentre que entre els anys 1360 i 1373 trobem a Jaume associat amb Eimeric Dusai com a canvista ${ }^{33}$. Com veiem, Jaume pare va acumular prou fortuna com perquè el seu fill Jaume ascendís de mercader a ciutadà, pogués obrir una taula de canvi associat amb Eimeric Dusai i actuar com a prestamista del rei.

Cal destacar que la capella dels Gualbes (sts. Mateu i Marta) i la dels Dusai (st. Rafael i Onze mil Verges) se situen una al costat de l'altra a l'església de Sta. Maria del Mar i també que, a través del matrimoni de

\footnotetext{
${ }^{26} \mathrm{AHMB}, \mathrm{CC}$, Fogatges, 1378, quarter del Mar, fol. 2v.

${ }^{27}$ Esteve Gilabert de BRUNIQUER, Rúbriques de Bruniquer. Cerimonial dels magnifichs consellers $i$ regiment de la ciutat de Barcelona, "Col-lecció de Documents Històrics inèdits del Arxiu Municipal de la ciutat de Barcelona", Barcelona, 1912-1916 (5 vols.), vol. 1, pp. 25 i ss.

${ }^{28} \mathrm{ADB}, \mathrm{RD}$, II, fols. 734r-736r, 6-4-1349.

${ }^{29} \mathrm{ACB}$, Speculum, II, fol. $103 \mathrm{r}$.

${ }^{30} \mathrm{AHPB}, 18 / 1$, fol. 33v, 2-5-1349: Jaume fill es refereix a Jaume pare com a quondam patris mei i a Ponç com a filio et herede una cum Johanne de Gualbis del difunt.

${ }^{31} \mathrm{AHPB}, 19 / 18$, fol. 106v, 13-5-1354.

${ }^{32}$ AHPB, 19/2, fol. 25r, 8-5-1363.

${ }^{33}$ AHPB, 19/23, fol. 50v, 15-2-1360, i 23/3, fol. 56r, 18-7-1373.

«Anuario de Estudios Medievales», 32/2 (2002), pp. 693-722 .- ISSN 0066-5061.
} 
Ferreró de Gualbes (fill de Ponç, germà de Jaume) amb Violant Dusai (filla de Raimon, cosí d'Eimeric), ambdues famílies estaven emparentades. Com veurem a l'arbre del final d'aquest article, aquestes famílies estaven igualment vinculades amb altres que també van promoure capelles, algunes d'elles a la mateixa Sta. Maria del Mar (Sapera) i d'altres a la Seu (Desvall, Almogàver), Sant Just (Marquet) i Sta. Maria del Pi (Desbosch).

\section{II.3. De mercader a creditor del rei $i$ vicealmirall de Catalunya: Bonanat Descoll}

Una altra via d'ascens social es troba en el fet d'haver acumulat una fortuna personal prou considerable per a poder realitzar préstecs a la monarquia, servei que sovint era recompensat amb la concessió de càrrecs oficials. El mercader Bonanat Descoll, promotor de la capella de st. Julià a Sta. Maria del Mar, n'és un bon exemple. L'any 1351 consta en els documents notarials com a Bonanatus de Colle, mercator $^{34}$, el $1356 \mathrm{com}$ a Bonanato de Colle, viceamiranto Cathalonie $e^{35}$, el 1360 com a conservatoris darasanarum domini regis ${ }^{36}$ i el 1364, ja difunt, com a creditor del rei, que li havia empenyorat ${ }^{37}$ :

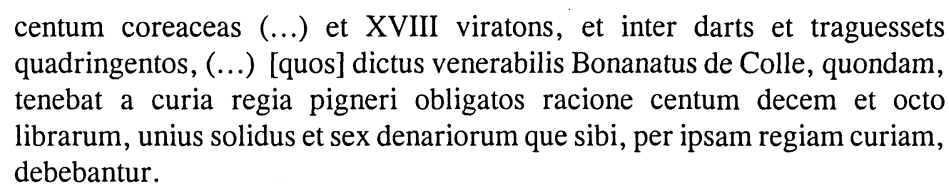
quadringentos, (...) [quos] dictus venerabilis Bonanatus de Colle, quondam, tenebat a curia regia pigneri obligatos racione centum decem et octo librarum, unius solidus et sex denariorum que sibi, per ipsam regiam curiam, debebantur.

\footnotetext{
${ }^{34}$ AHPB, 19/12, fol. 86v, 6-7-1351.

${ }^{35}$ AHPB, 17/4, fol. 73r, 17-10-1356.

${ }^{36}$ AHPB, 20/4, fol. 130v, 17-11-1360.

${ }^{37}$ AHPB, 23/15, fol. 45r, 28-6-1364.
} 


\section{ELS OFICIALS REIALS PROMOTORS DE CAPELLES: TRES EXEMPLES D' ASCENS SOCIAL}

Els funcionaris reials als quals ens referim són concretament els formats com a juristes, notaris i escrivans, que, tot i no tenir les fortunes personals d'alguns dels mercaders, també gaudien d'expectatives d'enriquiment i ascens social, sobretot a l'ombra de la cort reial. La projecció professional d'aquells juristes i notaris es desenvolupava en l'àmbit de l'administració reial, concretament la Cancelleria o la Tresoreria ${ }^{38}$. En tenim diversos exemples entre els promotors de capella estudiats: Bonanat Sapera, notari, tinent segell i conseller reial (capella dels sts. Pau i Praxedis, Sta. Maria del Mar); Pere Desbosch, escrivà de ració de la Tresoreria reial (capella de st. Miquel, Sta. Maria del Pi); Guillem Oliver, notari, inicialment també escrivà de ració de la Tresoreria i posteriorment secretari reial (capella de st. Pal-ladi, Seu), i Pere Desvall, tresorer reial (capella dels sts. Pere i.c. i Joan a.p.l., Seu) entre d'altres.

\section{III.1. De notari a cavaller: Bonanat Sapera, pare i fill}

Trobem esmentat per primer cop el notari Bonanat Sapera en la documentació de l'AHPB, 1'any 1333, com a tinent segell reial ${ }^{39}$ un dels oficis de la Cancelleria. En 1352 consta com a conseller del rei Pere ${ }^{40}$ i l'any següent com a notari i escrivà de la vicarie, duanie et portalanie de Castell de Càller (Sardenya ${ }^{41}$. Residia al carrer de Montcada ${ }^{42}$ i estava casat amb Francesca, germana de Raimon Dusai ${ }^{43}$, promotor de la capella de sant Rafael

${ }^{38} \mathrm{Veg}$. Tomàs de MonTagut, Els funcionaris i l'administració reial a Catalunya (ss. XIIIXIV), dins de La societat barcelonina en la baixa Edat Mitjana, Barcelona 1983, i El mestre racional a la Corona d'Aragó (1283-1419), vol. 1, Barcelona 1990.

${ }^{39} \mathrm{AHPB}, 8 / 1$, fol. 131r, 25-11-1333.

${ }^{40}$ AHPB, 19/15, fol. 68r, 11-5-1352, quondam.

${ }^{41} \mathrm{AHPB}, 19 / 9$, fol. 81r, 28-3-1353, quondam.

${ }^{42}$ AHPB, 14/2, fol. 124v, 23-11-1344.

${ }^{43}$ Ibidem, fol. 67r, 1-10-1344.

«Anuario de Estudios Medievales", 32/2 (2002), pp. 693-722 .- ISSN 0066-5061. 
i les Onze mil Verges de Sta. M. del Mar. Només tenim notícia d'una filla, Isabel, casada amb Andreu Marquès, i d'un fill, també anomenat Bonanat ${ }^{44}$. El seu oncle, Raimon Dusai, va actuar com a procurador de la seva mare per administrar uns drets i popietats que el difunt Bonanat percebia i posseïa a Sardenya, per tal de poder continuar el finançament de la capella que havia començat a promoure en vida ${ }^{45}$. Bonanat fill va continuar residint al carrer Montcada, com el seu pare ${ }^{46}$, però va ascendir encara un graó més en l'escala social, ja que en el padró de milícia de 1389 consta com a cavaller ${ }^{47}$, però sense que, malauradament, s'especifiqui la seva contribució. La capella, dedicada als sants Pau i Praxedis, és la primera de la girola, a mà esquerra, i du l'escut del promotor, amb la pera dels Sapera.

\section{III.2. D'escrivà de ració a senyor del castell de Vilassar: Pere Desbosch}

Des de l'any 1354 consta en la documentació notarial que Pere Desbosch treballava al servei del rei, però sense especificar l'ofici ${ }^{48}$. En 1360 se l'esmenta com a escrivà de ració de la Tresoreria ${ }^{49}$ i en 1363 com a conseller del rei Pere ${ }^{50}$. Des de l'any 1359 apareix com a senyor dels castells de Sant Vicens i Vilassar i ${ }^{51}$, per tant, ja com a membre de la petita noblesa. Estava casat amb Constança de Gualbes, filla del draper Ponç de Gualbes i néta del draper Jaume de Gualbes, que, com recordarem, va promoure una capella a Sta. M. del Mar. Però Desbosch, a més d'estar vinculat als Gualbes per raó del seu matrimoni, també va emparentar amb una altra família de relleu, els Desvall, gràcies al casament del seu fill, Pericó, amb la filla de

${ }^{44}$ Ibídem, fol. 124v, 23-11-1344.

${ }^{45}$ Ibidem, fols. 70r-72r, 4-10-1344.

${ }^{46}$ Ibídem, fol. $124 \mathrm{v}$ cit. sup.

${ }^{47}$ AHMB, CC, Fogatges, Padró de Milícia de 1389, quarter del Mar, fol. 19v.

${ }^{48}$ AHPB, 19/18, fol. 104v, 12-5-1354.

${ }^{49} \mathrm{AHPB}, 23 / 9$, fol. 44r, 21-5-1360.

${ }^{50} \mathrm{AHPB}, 23 / 14$, fol. 58v, 30-3-1363.

${ }^{51} \mathrm{AHPB}, 23 / 8$, fol. 5r, 19-2-1359.

«Anuario de Estudios Medievales», 32/2 (2002), pp. 693-722 .- ISSN 0066-5061. 
Pere Desvall, Marió ${ }^{52}$. Pere Desvall era tresorer reial ${ }^{53}$ i abans escrivà de la Tresoreria $^{54}$ de manera que treballava amb Pere Desbosch. Els capítols matrimonials d'aquella parella donen idea de la considerable riquesa dels seus pares. Cal destacar que Pere Desvall també va promoure una capella, situada al claustre de la Seu (la segona de l'ala paral-lela al c. de la Pietat) i dedicada als sants Pere i.c. i Joan a.p.l. A banda d'aquell fill, Pericó, en el testament de la seva dona, Constança de Gualbes, consta que en van tenir d'altres: Margarida, Miquel i Lluís ${ }^{55}$. Els Desbosch vivien al quarter de Framenors, in vico quo itur ad ecclesia Beate Marie Mercedis Barchinone ad voltas d'en Guayta $^{56}$, potser identificable amb el carrer Ample, i eren parroquians de Sant Miquel $^{57}$. Tot i això, Pere Desbosch va decidir promoure capella a Sta. M. del Pi i no a Sant Miquel, encara que va dedicar-la a sant Miquel i sant Esteve. La capella estava construïda l'any 1349 , data en què Desbosch va fundar-hi el benefici ${ }^{58}$, molt abans de morir, ja que no consta com a difunt fins el $1368^{59}$. Malgrat tot, en lloc de romandre fidel a la seva capella de l'església del Pi, va disposar el seu enterrament a la capella de st. Andreu, al claustre del convent de Framenors, però, com que ja tenia els escuts i el sepulcre dels Cervelló, li van concedir la de st. Aleix i les Verges ${ }^{60}$. El fet que instituís el benefici en vida i no per via testamentària, així com el fet que sol-licités una altra capella per al seu enterrament, en lloc d'escollir la que ja havia promogut, poden donar idea de la desofegada situació econòmica d'aquell oficial reial. La seva capella de l'església del $\mathrm{Pi}$, la cinquena del costat de l'Epístola (mà dreta), encara està oberta al culte, tot i que actualment està dedicada a la Immaculada.

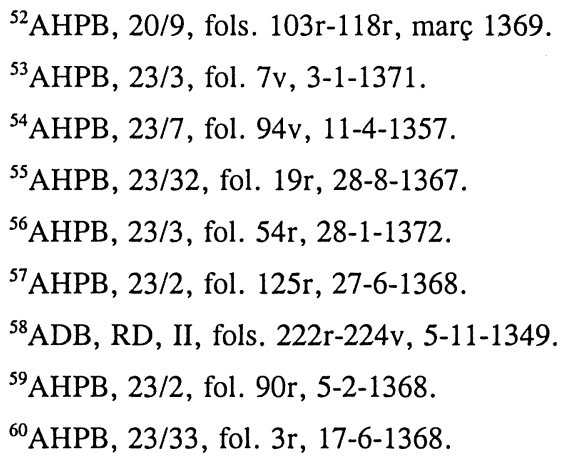


III.3. D'escrivà de ració a senyor del castell de Mataró: Pere de Marges

El causídic Pere de Marges apareix en la documentació de l'AHPB des del $1359^{61}$. En 1360 el trobem exercint el càrrec de mensuratoris ole ${ }^{62} \mathrm{i}$ no és fins 1361 que consta com a oficial de la Tresoreria reial i, per tant, treballant amb Pere Desbosch i amb Pere Desvall, que també van promoure capelles. Aquell mateix any apareix com a sotstresorer de Pere $\mathrm{III}^{63}$ i ja en 1367 com a escrivà de ració i conseller del rei ${ }^{64}$. També en 1367 localitzem el seu primer esment com a senyor del Castell de Mataró i, per tant, com a membre de la petita noblesa ${ }^{65}$. Era fill de Raimon de Marges, ciutadà ${ }^{66}$, i pare de Raimon, "de casa del duc"67. Aquest fill potser va morir, perquè és la seva germana Maria qui consta com a senyora del castell de Mataró en $1374^{68}$, després de morir el seu pare. Es diu que Pere de Marges residia prop del convent de Predicadors (Santa Caterina), situat al quarter de Sant Pere, però no s'indica en quin carrer ${ }^{69}$ :

hospicio venerabilis Petri de Marginibus, scriptoris porcionis domini regis, quodque hospicium est iuxta et satis prope domum fratrum predicatorum.

El fet que en el padró de milícia del 1389 no s'esmenti cap dels seus possibles descendents al quarter de Sant Pere i que, en canvi, apareguin un

${ }^{61} \mathrm{AHPB}, 23 / 8$, fol. 81v, 14-5-1359.

${ }^{62} \mathrm{AHPB}, 13 / 1$, fol. 188r, 7-10-1360.

${ }^{63} \mathrm{AHPB}, 19 / 1$, fol. 90r, 7-10-1361.

${ }^{64}$ AHPB, 20/9, fol. 22r, 22-12-1367.

${ }^{65}$ Ibídem.

${ }^{66} \mathrm{ADB}, \mathrm{RD}, \mathrm{I}$, fols. $342 \mathrm{r}-343 \mathrm{v}, 20-8-1372$ i 5-11-1373: fol. 342r.

${ }^{67} \mathrm{AHPB}, 28 / 2$, fol. 75v, 8-6-1373.

${ }^{68} \mathrm{AHPB}, 17 / 7$, fol. $98 \mathrm{v}, 30-5-1371$.

${ }^{69} \mathrm{AHPB}, 15 / 22$, s. f., 24-2-1368.

«Anuario de Estudios Medievales», 32/2 (2002), pp. 693-722 .- ISSN 0066-5061. 
Ramon i un Ramonet de Marges al de Framenors ${ }^{70}$ podria suggerir que en aquell document s'hagués escrit predicatorum per minorum. Pocs anys abans de morir havia decidit continuar la promoció de la capella iniciada pel canonge francesc Rufàs al claustre de la Seu (la primera de l'ala paral-lela al c. de la Pietat), que, com explica Marges a l'acta de dotació beneficial, havia quedat a mig construir ${ }^{71}$ :

ffuit delliberatum per me quod ego, pro Dei servicio et reverencia, facerem continuari perfici opus dicte capelle, la qual manserat incompleta, non multum elevata a terra.

Pere de Marges la va dedicar als sants Genís i Jordi i allà hi va disposar la seva sepultura. L'escut familiar d'aquest promotor, amb ones travessades per una banda carregada amb tres grius ${ }^{72}$, presideix els murs de la capella.

\section{ESTRATÈGIES DE CONSOLIDACIÓ I ASCENS SOCIAL}

\section{IV.1. El càrrec i l'ocupació professional}

Hem pogut veure que un cop aconseguit l'ascens cap a la ciutadania l'únic graó que restava per escalar era el de l'ennobliment, però la seva consecució comportava la pèrdua del dret a intervenir en el govern de la ciutat. Per aquesta raó no era estrany que una mateixa família tingués repartits els seus membres entre ciutadans honrats i cavallers. Segons Sobrequé $\mathrm{s}^{73}$ la

\footnotetext{
${ }^{70}$ Pere de Marges tenia un fill anomenat Raimon, "de casa del duc", hereu universal seu (AHPB, 28/2, fol. 75v, 8-6-1373); AHMB, CC, Padró de Milícia de 1389, quarter de Framenors, fols. 75r i 211r: Raimon de Marges contribueix amb dos arnesos, de manera que se li pot calcular una fortuna entre 50.000 i 80.000 sous (veg. A. GARCIA I ESPUCHE-M. GUÀRDIA, La ciutat consolidada, dins d'Història de Barcelona, vol. 3, Barcelona 1992, p. 49), és a dir, entre 2.500 i 4000 lliures.

${ }^{71} \mathrm{ADB}, \mathrm{RD}, \mathrm{I}$ cit. sup., fol. $342 \mathrm{v}$.

${ }^{72}$ Francisco Xavier de GaRma, Adarga catalana, llibre II, València 1992 (ed. facsímil), p. 148; Ramon PIÑol I ANDREU, Heràldica de la Catedral de Barcelona, Barcelona, 1948, p. 181.

${ }^{73}$ Jaume SOBREQUÉS, La nobleza catalana en el siglo XIV, "Anuario de Estudios Medievales", 7 (Barcelona 1970-1971), p. 514.

«Anuario de Estudios Medievales», 32/2 (2002), pp. 693-722 .- ISSN 0066-5061.
} 
pràctica habitual era destinar la branca primogènita, la de més prestigi social i econòmic, a la ciutadania, mentre que la secundària es destinava a la cavalleria. En conseqüència cal insistir en què els estaments baixmedievals no constituïen pròpiament classes socials en l'accepció actual del terme, sinó que s'han d'imaginar com a "microsocietats", amb les seves pròpies aristocràcies, estrats mitjans i inferiors. En funció d'aquest enfocament, podem suposar que un cavaller fincat a la ciutat se sentiria més proper a un ciutadà honrat que no pas a un donzell confinat a les seves terres, mentre que el ciutadà honrat se sentiria més proper a aquell cavaller que no pas a un mercader modest. Aquest fenomen explica la tendència d'alguns membres de la petita noblesa i del patriciat urbà a practicar enllaços matrimonials entre ells, ja que si uns aportaven rendes sanejades en canvi els altres aportaven un cognom ennoblit. La documentació notarial consultada porporciona algunes notícies relatives a la pràctica seguida per les grans famílies barcelonines de destinar un fill a la continuació del negoci familiar i l'altre a la cort. En tenim un exemple en Ferrer de Gualbes, promotor de capella a Sta. M. del Mar: el seu fill Bernat consta com a "draperius" i, per tant, com a continuador del negoci familiar, mentre que en canvi el seu fill Simó consta com a "de domo domini regis"74.

Hi havia una sèrie d'oficis reials que, segons sembla, no estaven reservats a cap col-lectiu professional concret, com el de batlle general, veguer, sotsveguer, batlle local, almirall o vicealmirall, alguns dels quals van ser exercits per alguns dels qui van promoure capella o donar retaule a la Seu i a les grans esglésies parroquials de Barcelona. Entre ells trobem: Jaume de Rocafort, mercader, després ciutadà i batlle general del regne d'Aragó ${ }^{75}$ (capella dels sts. Tomàs i Antoni de P., Seu); Francesc de Togores, cavaller i veguer de Barcelona ${ }^{76}$ (marit de Guillemona de Barberà: capella i retaule de st. Gabriel, Seu); Francesc de Santcliment, ciutadà honrat i després cavaller ${ }^{37}$,

${ }^{74} \mathrm{AHPB}, 23 / 15$, fol. 131v, 3-12-1364.

${ }^{75}$ AHPB, 19/5, fol. 315r, maig 1349; 23/2, fol. 27r, 24-2-1367; 20/2, fol. 18r, 15-5-1364.

${ }^{76}$ AHPB, 13/6, fol. 31r, 1349; 19/22, fol. 122v, 28-8-1360.

${ }^{77} \mathrm{AHPB}, 23 / 32$, fol. 34r, 21-11-1370; 25/1, fol. 44, 5-3-1366.

«Anuario de Estudios Medievales», 32/2 (2002), pp. 693-722 .- ISSN 0066-5061. 
també veguer de Barcelona ${ }^{78}$ (marit de Bartomeua Bou: capella i retaule dels sts. Bartomeu i Elisabet d'H., Seu); Joan Sabastida, ciutadà i batlle de Barcelona $^{79}$ (retaule de la capella de st. Andreu, Seu); Bonanat Descoll, mercader, després ciutadà i vicealmirall de Catalunya ${ }^{80}$ (capella de st. Julià, Sta. M. del Mar), etc.

Pel que fa al govern municipal, durant el segle XIV, el Consell de la ciutat va estar controlat per les famílies de molts d'aquells promotors de capelles, o fins i tot per ells mateixos. Així, trobem monopolitzant el càrrec de conseller en cap als Marquet (Antígona Marquet: capella de st. Simeó, St. Just), els Llull (ardiaca Bernat Llull: capella del Corpus, Sta. M. del Mar), Francesc de Santcliment (1334, marit de Bartomeua Bou: capella dels sts. Bartomeu i Elisabet, Seu), Arnau Dusai (1347, pare de Raimon Dusai: capella de st. Rafael i les Verges, Sta. M. del Mar), Guillem Oliver (1348 1350, 1352 i 1355, capella de st. Pal-ladi, Seu), Berenguer Vives (1351, capelles dels sts. Pere i Pau i de st. Iu, Sant Just), Jaume Cavaller (1354, 1357 i 1360, capella de st. Jordi, Sta. M. del Mar), Pere Terré (1377, fill de Pere Terré: capella de st. Pere, Sta. M. del Pi), etc. ${ }^{81}$. Es tracta d'individus amb diferent formació (canvistes com Jaume Cavaller, notaris com Guillem Oliver o juristes com Berenguer Vives) i dedicats a ocupacions diverses (oficials reials com el ja esmentat Guillem Oliver, escrivà de ració de la tresoreria reial, o canviadors com Jaume Cavaller), però sovint pertanyents a famílies de llarga tradició (la rellevància dels Marquet, els Dusai o els Llull a Barcelona es remunta al s. XIII). D'aquí l'interès a centrar-nos en aquells promotors de capella que van escalar posicions en l'escala social per ells mateixos, ja fos amb l'obtenció d'alts càrrecs a palau o en el govern, ja fos amb l'ingrés dins la petita noblesa.

\footnotetext{
${ }^{78}$ AHPB, 20/4, fol. 88r, 3-11-1360 i 19/2, fol. 25v, maig 1363. Sobre els veguers veg. J. SERRA I ROSElló, Cronologia de los "veguers de Barcelona", "Documentos y estudios", 5 (1961).

${ }^{79} \mathrm{AHPB}, 79 / 1$, fol. 16v, 14-6-1399.

${ }^{80}$ AHPB, 19/12, fol. 86v, 1351; 23/15, fol. 45r, 28-8-1364; 17/4, fol. 73r, 17-10-1356.

${ }^{81}$ El Llibre del Consell (AHMB, Consell de Cent, Llibre del Consell) i BRUNIQUER (Rúbriques, vol. 1, p. 25 i ss.) faciliten els noms dels consellers i dels jurats representants de cada estament.
}

«Anuario de Estudios Medievales», 32/2 (2002), pp. 693-722 .- ISSN 0066-5061. 
Com es pot suposar, el poder dels nostres promotors de capella no era tan sols polític sinó també econòmic. El padró de milícia de 1389 , font indispensable per conèixer la quantia de les grans fortunes barcelonines $\mathrm{d}$ 'aleshores, és de data massa tardana perquè hi constin alguns dels promotors de capella estudiats, però, si més no, hi apareixen els seus hereus. Resulta molt significatiu que la contribució màxima (tres arnesos) fos pagada per deu d'aquells promotors o pels seus hereus, obligada per als qui posseïen fortunes superiors a 80.000 sous $(=4000 \text { lliures })^{82}$. En el quarter de Framenors consten: la vídua del mercader Pere Safont (capella de sta. Eufrasina, Seu), Genís Almogàver (tercer fill del mercader Guillem Almogàver, capella dels sts. Macià i Helena, Seu), Berenguer Vives (fill del jurista del mateix nom, capelles dels sts. Pere i Pau i de st. Iu, Sant Just), Joan, Ferrer i Ponç de Gualbes (possibles descendents de Ponç, Francesc i Bernat, mercaders i canvistes, capella dels sts. Mateu i Marta, Sta. M. del Mar) ${ }^{83}$. En el quarter de Sta. M. del Mar consten: Raimon Savall (fill del mercader del mateix nom, capella de st. Esteve, Sta. M. del Mar), el mercader Guillem de Cabanelles (fill del mercader del mateix nom, capella dels sts. Guillem i Elisabet, Sta. Maria del Pi), Guillem Oliver (fill del notari i secretari reial del mateix nom, capella de st. Pal·ladi, Seu) i Bernat Serra (nét del promotor del mateix nom, capella dels sts. Jaume i Vicenç, Sta. M. del Pi) ${ }^{84}$. Finalment, en el quarter de Sant Pere consten: Joan Desvall (fill del tresorer reial Pere Desvall, capella dels sts. Pere i.c. i Joan a.p.1., Seu) i Joan Sabastida (retaule de st. Andreu, $\mathrm{Seu})^{85}$. També és molt significatiu que d'aquests deu rics promotors de capella cinc fossin mercaders i dos oficials reials de palau.

Hem pogut veure que els membres d'aquest sector social podien enriquir-se amb l'exercici d'un ofici reial, com Bonanat Sapera, scriptoris domini regis ac notarii et scriba vicarie, duanarie et portalanie Castri Calerii,

${ }^{82}$ GARCIA I ESPUCHE-GUÀRDIA, La ciutat consolidada, p. 49.

${ }^{83}$ AHMB, CC, Fogatges, Padró de milícia de 1389, quarter de Framenors, fols. 75r i 211r (Safont), fols. 76r i 211v (Almogàver), fol. 86v (Vives) i fols. 70r i 209r, fols. 79r i 212r, fols . $85 \mathrm{v}$ i $213 \mathrm{v}$, fols. 58r i 206r (Ponç, Jaume, Francesc i Joan de Gualbes, respectivament).

${ }^{84}$ Ibídem, quarter del Mar, fols. 10r i 221r (Savall), fols. 20r i 222r (Cabanelles), fol. 40r (Oliver) i fols. 40r i 226v (Serra).

${ }^{85}$ Ibidem, quarter de Sant Pere, fols. $139 v$ i 234 r (Desvall) i fols. $140 v$ i $234 v$ (Sabastida). 
el qual va adquirir diversos drets i propietats a Sardenya que després va destinar al finançament del benefici i la capella que va promoure a Sta. M. del Mar. També podien acabar senyorejant castells i llocs, com l'escrivà de ració Pere Desbosch, domino castrorum de Sancto Vicencio et de Vilassario, promotor d'una capella a Sta. Maria del Pi, o el causídic Pere de Marges, "domino dicti castri de Matarone", promotor d'una capella al claustre de la Seu. Però, com veurem a continuació, totes aquestes gestions solien anar acompanyades d'una bona política matrimonial.

\section{IV.2. Politiques matrimonials}

La prosperitat econòmica obria les portes al prestigi social, de manera que no només es vetllava pel bon funcionament del negoci, sinó també per la política matrimonial de la família. Aquest tema ens porta a parlar novament de la promoció particular de capelles a la Seu i les tres grans esglésies parroquials, un dels signes externs d'aquell prestigi. S'han localitzat dos testaments a l'AHPB que permeten conèixer els vincles existents entre algunes de les famílies més rellevants de la Barcelona del s. XIV, totes elles relacionades amb la promoció de capelles. Es tracta de dos testaments relacionats amb les famílies Dusai i Gualbes: el d'Isabel, nora de Raimon Dusai, i el de Violant, filla de l'anterior i nora de Ponç de Gualbes. Com ja s'ha dit, ambdues famílies havien obtingut capelles a Sta. Maria del Mar i, a més, contigües: la dels sts. Mateu i Marta i la de st. Rafael i les Onze mil Verges. Trobem, doncs, relacionats a través d'Isabel: els Olivella, avi matern del marit; els Dusai, sogres (promotors de capella), i els Desvall, cosins seus (promotors de capella). En canvi, a través de Violant trobem relacionats: els Gualbes, sogres (promotors de capella); els Dusai, pares (promotors de capella); Bonanat Almogàver, cunyat (fill de promotor de capella); els Marimon, els Sapera (promotors de capella) i els Conomines, tots cosins seus; els Sabastida i els Serra i, finalment, els Bussot, oncles seus. D'altres documents notarials han permès ampliar encara més aquesta xarxa de parentius amb la incorporació de més famílies a través d'enllaços matrimonials: els Marquet (promotors de capella) amb els Gualbes, els Desbosch (promotors de capella) també amb els Gualbes i els Desvall (promotors de capella) amb el Desbosch.

«Anuario de Estudios Medievales», 32/2 (2002), pp. 693-722 .- ISSN 0066-5061. 
De totes aquestes famílies només s'han inclòs a l'arbre que presentem a continuació aquelles relacionades amb la promoció de capelles a la Seu o a les tres grans esglésies parroquials. Sens dubte resulta molt significatiu que l'ocupació professional dels seus membres es redueixi a dos sectors: mercaders (Gualbes, Dusai, Almogàver) i oficials reials (Desvall, Desbosch, Sapera). Igualment, també crida l'atenció el fet que gairebé la meitat d'ells protagonitzessin ascensos socials o els facilitessin als seus fills: Jaume de Gualbes pare (draper) i fill (canvista, creditor del rei), Pere Desbosch (escrivà de ració i senyor del castell de Vilassar), i Bonanat Sapera pare (notari i tinent segell reial) i fill (cavaller). Tot plegat un bon exemple de l'íntima relació existent entre context politicoeconòmic (expansió política i comercial), socioeconòmic (prosperitat $i$ ascens social) i urbà (dinamisme constructiu reial, municipal i eclesiàstic). D'aquí que les capelles d'aquelles esglésies gòtiques apareguin com el testimoni material explícit de tot aquell fenomen, com el recordatori tangible de tots aquells ascensos i consolidacions socials ja oblidats. 


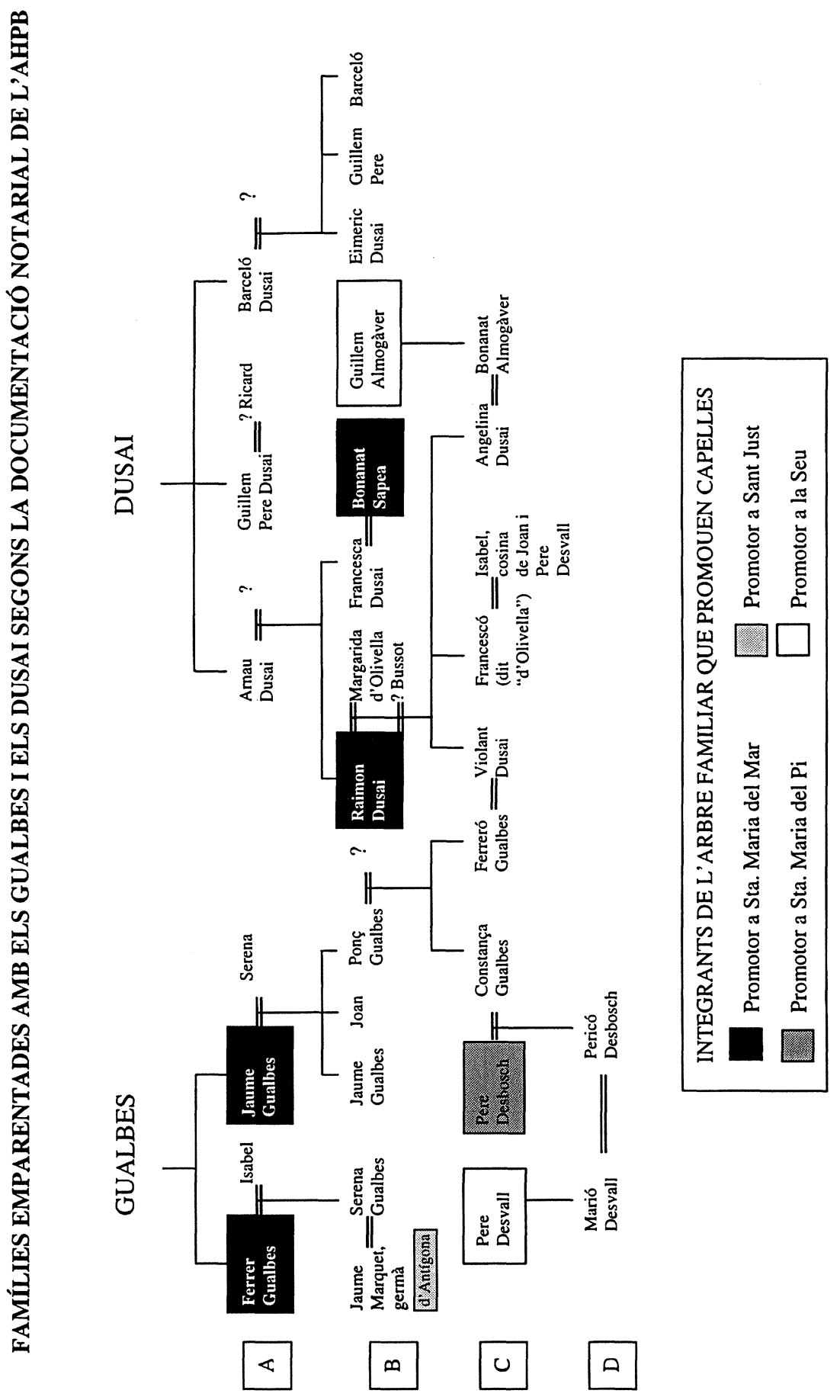


A. Jaume, Ferrer, Francesc i Bernat de Gualbes, germans: ADB, RD, II, fols. 734r736r, referència al testament de Jaume del 1348 i dotació del 1361.

B. Joan i Ponç de Gualbes, fills de Jaume i Serena: ibid. i ACB, Speculum, II, fol. 103r, referència al testament de Jaume del 1348.

Serena de Gualbes, filla de Ferrer i Isabel i dona de Jaume Marquet: AHPB, 23/5, fol. $35 \mathrm{v}, 1355$.

Joan i Ponç de Gualbes, germans de Jaume: AHPB, 18/1, fol. 33v, 1349.

Raimon Dusai, fill d'Arnau i germà de Francesca, dona de Bonanat Sapera: AHPB, 14/2, fols. 67r i 70, 1344; marit en primeres núpcies de Margarida d'Olivella: AHPB, 17/15, fol. 7r, 1367.

Guillem Almogàver, pare de Bonanat: AHPB, 23/18, fol. 6r, 1367.

Eimeric, Guillem Pere i Barceló Dusai, fills de Barceló: AHPB, 12/3, fol. 105r, 1342.

C. Pere Desvall, consogre de Pere Desbosch: AHPB, 20/9, fol. 103r, 1367 (capítols matrimonials).

Pere Desbosch, marit de Constança de Gualbes, filla de Ponç: AHPB, 23/32, fol. 19r, 1367.

Ferreró de Gualbes, fill de Ponç i marit de Violant Dusai; Violant, filla de Raimon Dusai, germana de Francescó i d'Angelina (entre d'altres); Violant, cosina de Bernat de Marimon, Bonanat Sapera fill i Francescó de Conomines; Violant, neboda de Bernat, Antoni, Guillem Pere i Raimon Bussot; Angelina Dusai, dona de Bonanat Almogàver: AHPB, 20/12, fol. 66r-68r, 1374 (testament de Violant Dusai). Bonanat Almogàver, fill de Guillem: AHPB, 23/18, fol. 6r, 1367 i 23/2, fol. 102v, 1367. Francescó Dusai, dit d' "Olivella", fill de Raimon Dusai, nét per via materna de G. d'Olivella: AHPB, 17/15, fol. 7r, 1367; marit d'Isabel, cosina de Joan i Pere Desvall : AHPB, 20/12, fol. 17v-19r, 1370 (testament d'Isabel).

D. Marió Desvall, filla de Pere, i Pericó Desbosch, fill de Pere, cònjuges: AHPB, 20/9, fol. 103r, 1367 (capítols matrimonials). 


\section{APÈNDIX DOCUMENTAL}

Capella dels sants Pere i.c. i Joan a.p.1., promoguda pel tresorer reial Pere Desvall després que li fos cedida pels marmessors testamentaris de Francesc d'Eiximenis, els quals l'anaven a dedicar a sant Francesc.

1375, gener, 3. Barcelona.

Acta de cessió de la capella promoguda pels marmessors testamentaris de Francesc d'Eiximenis a Pere Desvall, a canvi de la restitució de l'import que aquells havien pagat. Aquest document constitueix un exemple de com podia variar la identitat del promotor d'una capella i la seva advocació fins $i$ tot abans que estigués acabada, cosa que pot arribar a complicar extraordinariament el seguiment del seu historial. Com veiem, la cessió dels drets adquirits sobre ella també era un acte que, necessariament, calia legitimar davant de notari, per tal d'evitar reclamacions i fins i tot plets posteriors. Igualment, aquesta acta ens informa de l'estat en què es trobaven aleshores les obres de la capella: "incepta et usque ad medium vel quasi". Sense la localització d'aquest document no es compendria la presència de l'escut dels Desvall a la capella, ja que només s'ha conservat l'acta de dotació del benefici d'Eiximenis $(A D B)$ i la de concessió de la capella als seus marmessors $(A C B)$, mentre que, en canvi, s'ha perdut la documentació del benefici fundat per Desvall.

AHPB, F. de Ladernosa, 23/3, s. f.

Instrumentum factum venerabile Petro de Vallo pro venerabile Petro Ça Costa [...] venerabile Gisperti Dexiaminç, quondam, et domine Blanche, quondam sororis dicti Gis[perti...], venerabili Eymerici de Sarriano, quondam, et manumissorem et cetera subrogatum testamenti [...] Examiniç, quondam fratris dictorum Gisperti et domine Blanche, et per venerabile Andrea [de Me]dalia, manumissorem testamenti dicte domine Blanche, in quo instrumento concedunt et difinunt dicto Petro de Vallo illam capellam que est incepta et usque ad medium Ivel quasi/ continuata in Sede barchiononense, in claustro, scilicet, novo ipsius Sedis, Icontigua inmedia[te]/ portali ipsius claustri quod aperit versus Meridie. Quamquidem capellam domini

«Anuario de Estudios Medievales», 32/2 (2002), pp. 693-722 .- ISSN 0066-5061. 
episcopus et Capitulus concesserant et assignaverant Ipro certa peccunie quantitate/ dictus manumissoribus ad opus altaris et prebiteratus que ibi, per ipsos manumissores, fieri debebant sub invocacione beati Ffrancisci de bonis dictarum manumissoriarum.

Ita quod [dictus] Petrus de Vallo, dando Operi dicte Sedis illam peccunie quantitatem, quam dicti manumissores, iuxta convencionem [...] inter ipsos manumissores et dictos dominos episcopum et Capitulum factam, dare debebant, possit [...] dictam capellam accipere ad opus altaris et prebiteratus quos ibi vult instituere, sub illa invocacione de qua [...] videbitur, et ibi facere sepulturam et signa sua, et cetera. Constat enim quod dicti prebiteratus dictorum manumissorum deservitur iam hodie in altari antiquo sancti Francisci in dicta Sede constructo, et quod dicti domini episcopus et Capitulum assignarunt, ut d[icitur], dictis manumissoribus alium idoneum locum in dicta Sede pro dicto prebiteratu manumissoriarum predictarum, et cetera. Fiat large, non est alia nota. 


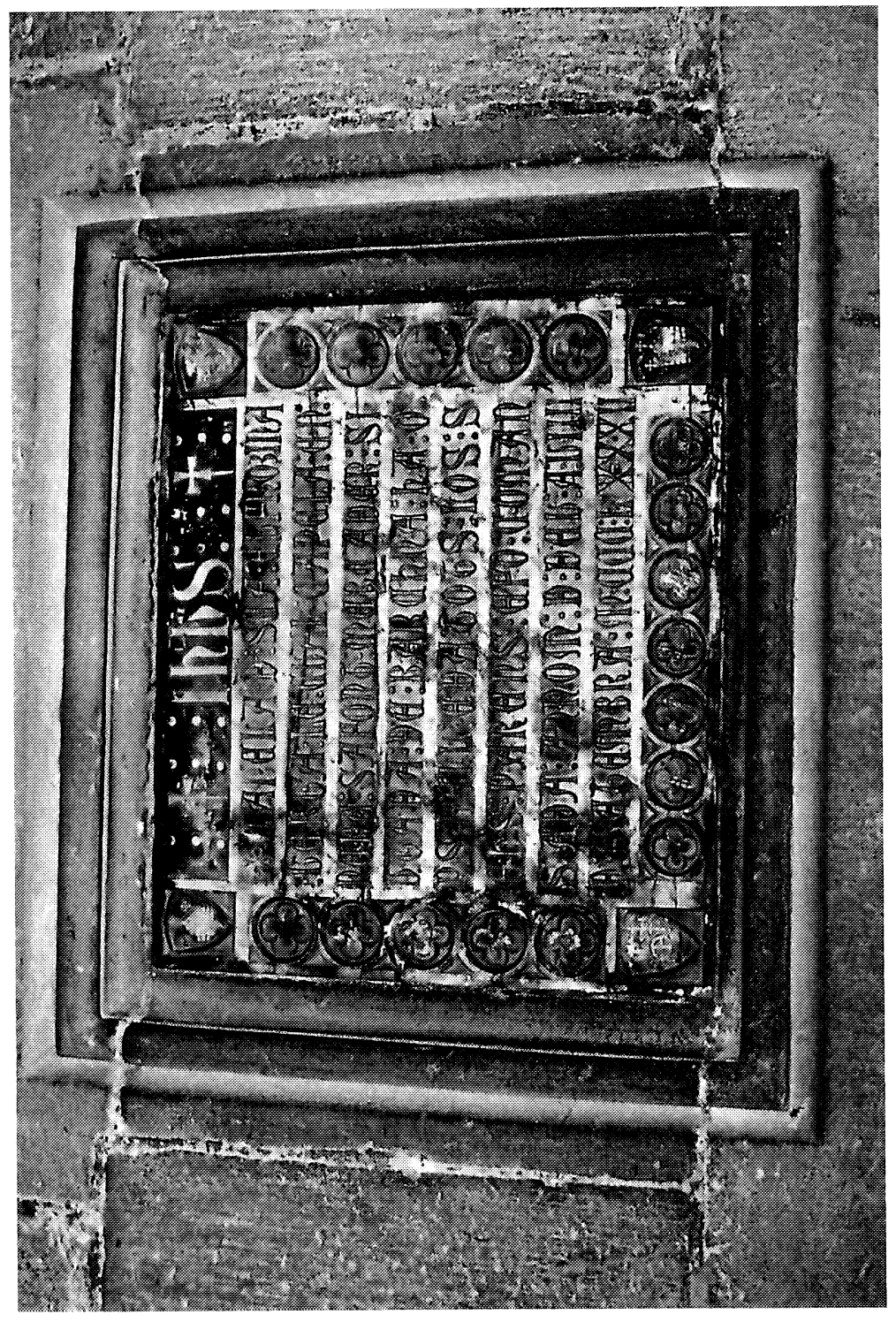

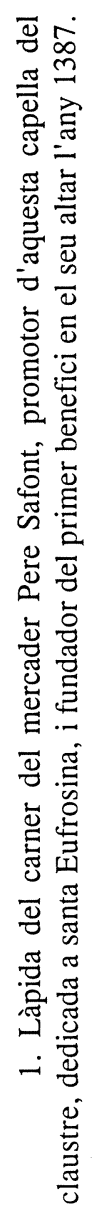



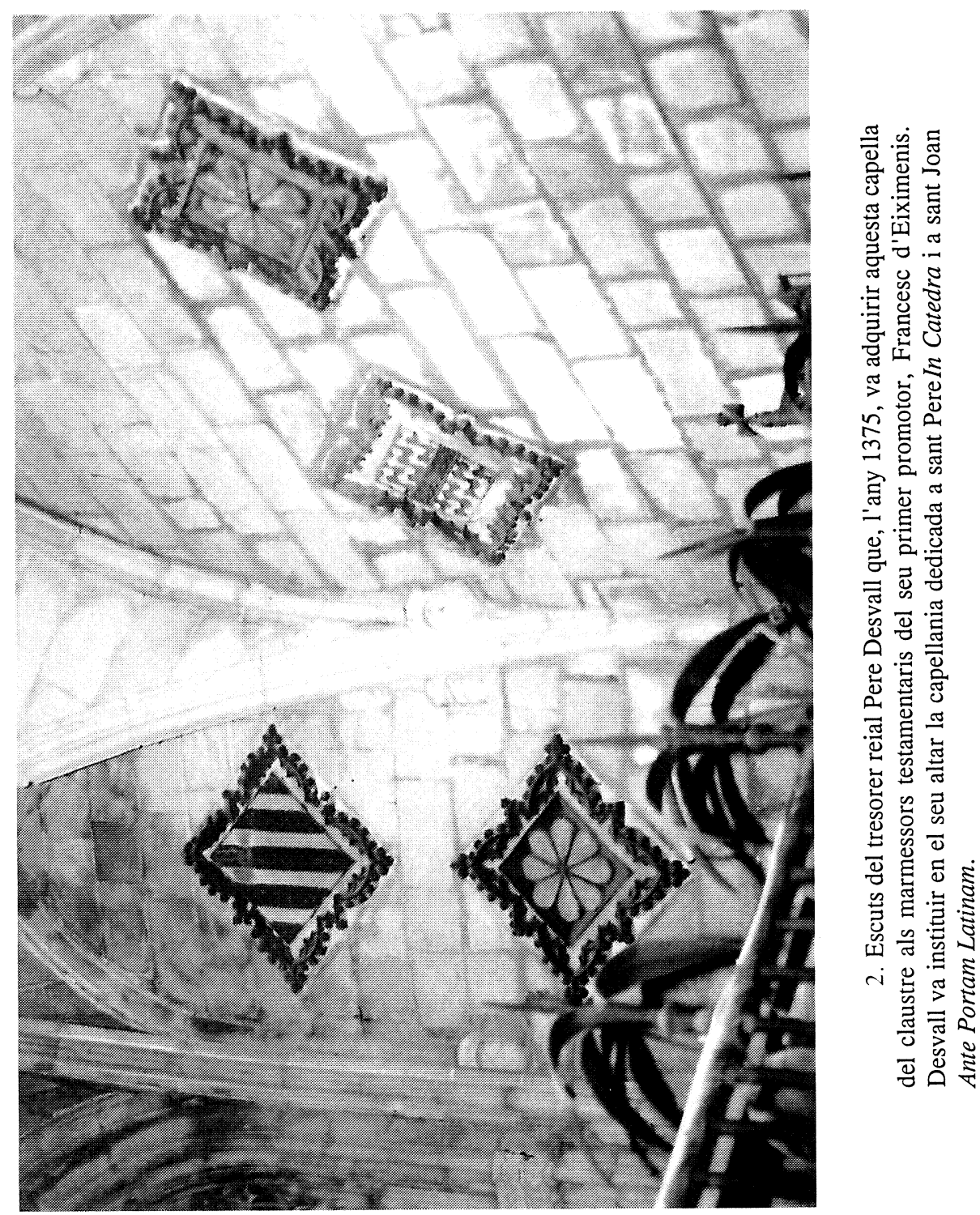


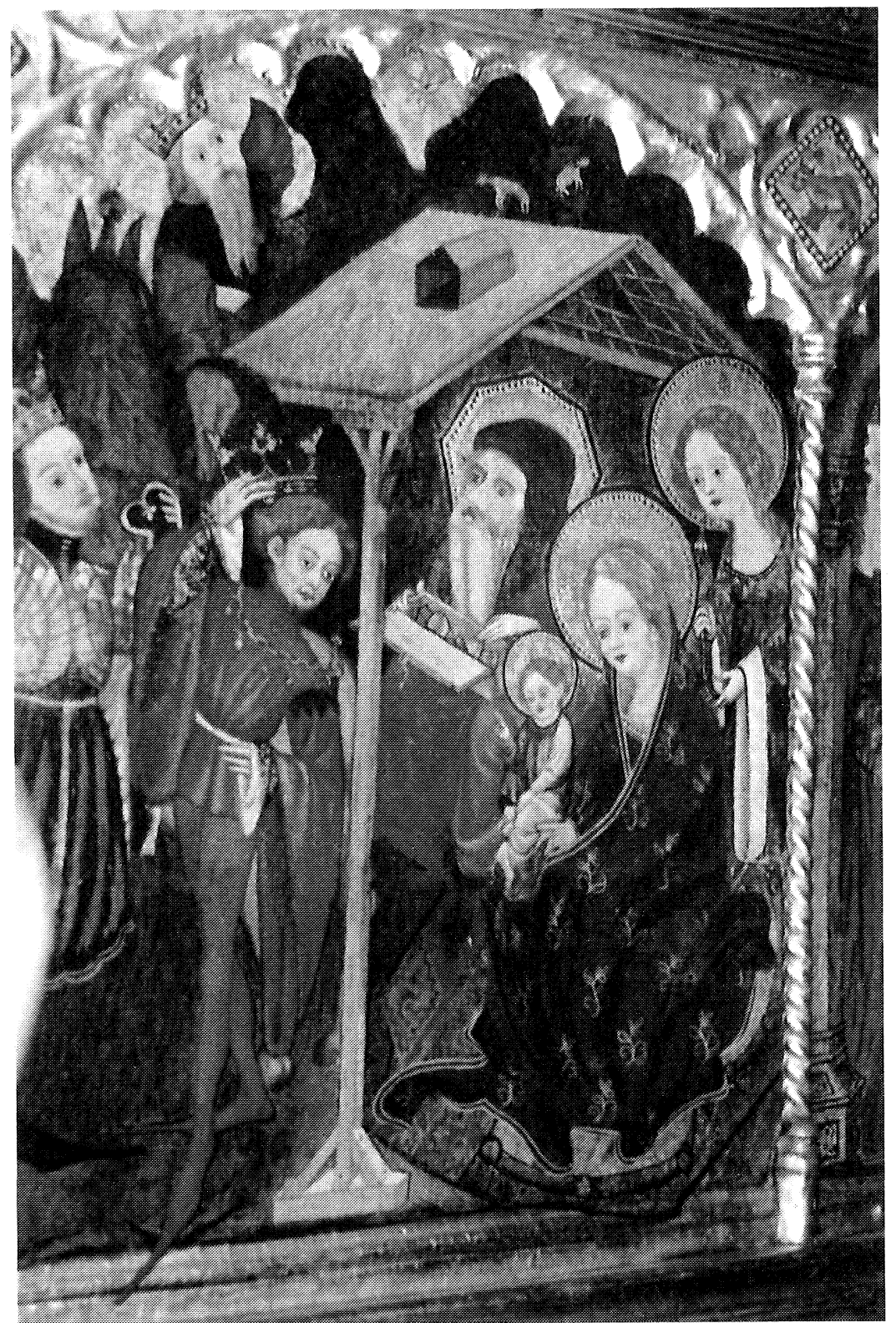

3. Compartiment lateral (amb l'Epifania) del retaule de sant Bartomeu i santa Elisabet d'Hongria de la Seu, pintat per Guerau Gener el 1401. Du l'escut de Bartomeua Bou, promotora de la capella, i el del seu marit, Francesc de Santcliment. 


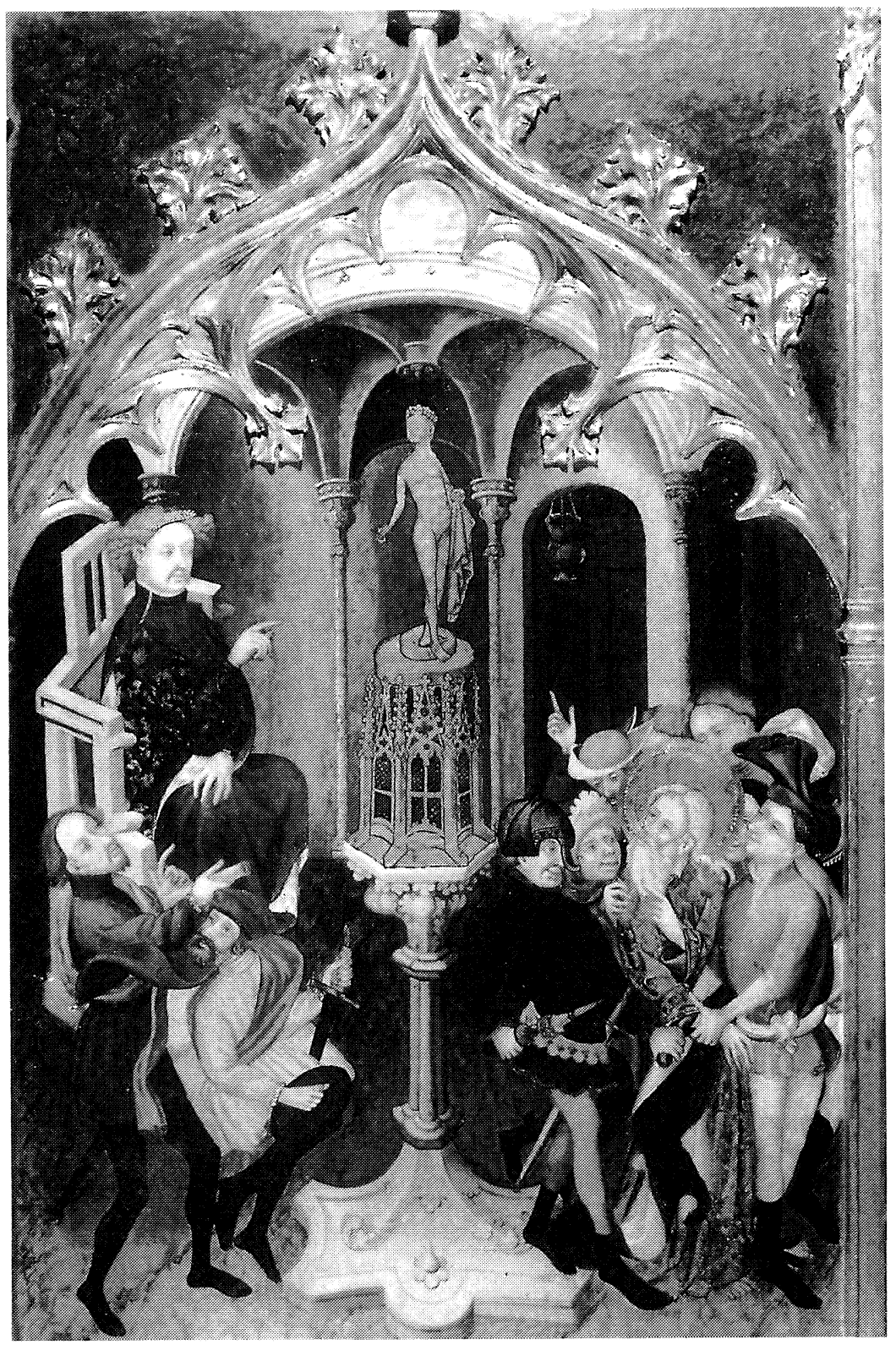

4. Compartiment lateral del retaule de sant Andreu de la Seu, atribuït a Lluís Borrassà (col-lecció privada). Representa la negativa de Sant Andreu a adorar els ídols pagans. Va ser donat per Joan Sabastida, fundador del quart benefici dedicat a aquell sant l'any 1388 . 